\title{
Experimental \& Numerical Study on Thermal Conductivity of Rice Husk Filled Epoxy Composites
}

\author{
Ramesh Chandra Mohapatra \\ Mechanical Department, Government College of Engineering, Keonjhar, India \\ Email: rameshmohapatra75@gmail.com
}

How to cite this paper: Mohapatra, R.C. (2018) Experimental \& Numerical Study on Thermal Conductivity of Rice Husk Filled Epoxy Composites. Open Access Library Journal, 5: e4661.

https://doi.org/10.4236/oalib.1104661

Received: May 15, 2018

Accepted: July 13, 2018

Published: July 16, 2018

Copyright (c) 2018 by author and Open Access Library Inc.

This work is licensed under the Creative Commons Attribution International License (CC BY 4.0).

http://creativecommons.org/licenses/by/4.0/ (c) (i) Open Access

\begin{abstract}
In the present work, thermal conductivity of rice husk ( $200 \mu \mathrm{m}$ mesh size) filled epoxy composites has been studied experimentally \& numerically. In this study, a successful fabrication of a rice husk filled epoxy composite with different filler content is possible by hand lay-up technique. An experimental approach was used to determine the thermal conductivity of rice husk filled epoxy composites using Lee's apparatus. The result shows that for each size of rice husk, the thermal conductivity of composite decreases with increase of filler contents which indicates that the rice husk reinforced epoxy composites have good insulation properties. In addition to experimental analysis, a commercially available finite-element package ANSYS is used to for the numerical analysis. Comparison graphs were plotted for both experimental and numerical analysis. The thermal conductivities of both the methods are very close to each other. The slight deviation between these two is due to the assumptions taken for the FEM analysis that are not real.
\end{abstract}

\section{Subject Areas}

Mechanical Engineering

\section{Keywords}

Thermal Conductivity, Epoxy, Rice Husk, Lee's Apparatus, Finite Element Method, Ansys

\section{Introduction}

Processing of plastic composites using natural fibres as reinforcement has increased dramatically in recent years. The advantages of composite materials 
made of natural fibres over conventional materials are weight saving, lower raw material price, recyclable and renewable. Natural fibre reinforced plastic composites have been increasingly utilised in quite widespread applications. They are used in transportation such as automobiles, railway coaches, aerospace etc., military applications, building and construction industries (ceiling, panelling, and partition boards), packaging, consumer products etc. Natural fibres include those made from plants, animal and mineral sources.

The improvement of the insulating properties of composites can be determined by measuring their thermal properties i.e. the values of thermal conductivity. Generally thermal conductivity is a property which has ability to conduct heat of materials. It plays an important role in determining their heat conduction/insulation capability. Some studies have investigated the thermal conductivity of wood based composites, but few have explored the thermal conductivity of natural fibre and thermoplastic composites. Russell [1] \& Maxwell [2] theoretical models have been widely applied for predicting thermal conductivity of multi-phase composites. Maclean [3], Kollman [4], Wikes [5], Tenwolde et al. [6] and Kamke [7] reviewed the empirical equations for predicting the thermal conductivity of wood and wood based panel products. Rout et al. [8] studied the effective thermal conductivity, coefficient of thermal expansion (CTE) and glass transition temperatures $(\mathrm{Tg})$ of rice husk filled polymer composites. From the results, it was found that the effective thermal conductivity (Keff.) and CTE of neat epoxy are reduced by $74.38 \%$ and $22 \%$ respectively and the $\mathrm{Tg}$ is increased by $140 \mathrm{C}$ with addition of (15 wt.\%) rice husk content. Mohapatra et al. [9] found that the thermal conductivity of pine wood dust-filled epoxy composites decreased as filler content increased. Vishnu et al. [10] focused on the maximum utilization of abundantly available industrial waste fly ash in a useful manner. The thermal properties of the composites, like Thermal conductivity, Specific heat capacity, Linear coefficient of Thermal expansion and Thermal diffusivity, were experimentally determined in the engineering laboratory. The results showed that increase of fly ash percentage in composite increases the thermal properties, which enhances thermal insulation capability of reinforced epoxy composites.

The objective of this research is to investigate the effect of density on the thermal conductivity of rice husk filled epoxy composites with varying proportions of rice husk filler. A finite element method was fitted for describing the thermal conductivity of these composites and was compared with the experimental results derived for rice husk based materials and theoretical models for multi-phase mater.

\section{Theoretical Investigations}

The composite is usually prepared based on calculation of weight fractions or volume fractions (Table 1). In this research volume fraction was taken into consideration. The density of the composite is found out by rule of mixtures. As per rule of mixtures, the density of the composite is obtained by 
Table 1. Properties of Pine wood dust and Epoxy.

\begin{tabular}{ccc}
\hline Properties & Rice husk & Epoxy \\
\hline Density $(\mathrm{g} / \mathrm{cc})$ & 0.12 & 1.1 \\
Thermal conductivity $(\mathrm{W} / \mathrm{m}-\mathrm{K})$ & 0.042 & 0.363 \\
\hline
\end{tabular}

$$
\rho_{c}=\rho_{m} v_{m}+\rho_{f} v_{f}
$$

where $\rho_{c}=$ Density of the composite, $\rho_{m}=$ Density of the matrix, $\rho_{f}=$ Density of the filler.

If $v_{f}=$ Volume fraction of filler, $V_{f}=$ Volume of the filler, $V_{m}=$ Volume of the matrix and $V_{V}=$ Volume of voids, then the volume fraction of the filler

$$
v_{f}=\left[\frac{V_{f}}{V_{f}+V_{m}+V_{v}}\right] \times 100
$$

where Volume of the composite

$$
V_{c}=V_{f}+V_{m}+V_{v}
$$

The measured density $\left(\rho_{a}\right)$ of the composite was determined experimentally by using water immersion technique. Considering theoretical density and actual density, the volume fraction of the void is calculated as follows

$$
V_{v}=\frac{\rho_{c}-\rho_{a}}{\rho_{c}}
$$

\section{Experimental Investigations}

\subsection{Materials}

The rice husk collected from local vendor of $200 \mu \mathrm{m}$ mesh size measured through sieve shaker was considered as filler material in fabrication of the composite. Epoxy LY 556 and Hardener HY 951 supplied by Hindustan Ceiba Geigy India Ltd has been used as matrix material. A metallic mould has been developed in house to cast for thermal conductivity testing. After mixing epoxy and pine wood dust in proper ratio the composite was cast by pouring into the split mould. The cast of each composite was cured under a load of about $50 \mathrm{~kg}$ for 24 hours before it was removed from the mould. Then this cast was post cured in air for another 24 hours after removing out from the mould (Figure 1).

\subsection{Experimental Setup}

The thermal conductivity test is carried out with Lee's disc apparatus shown in Figure 2. The Nickel disc $(\mathrm{N})$ is hung from the stand with the help of three strings. A heating chamber $(\mathrm{H})$ with facility of passage of steam in and out is created. Metallic disc (M) is placed on the top of a heating chamber $(\mathrm{H})$. Sample disc $(\mathrm{S})$ is placed in between metal disc and nickel disc. Two holes are made in the nickel disc $(\mathrm{N})$ and metallic disc $(\mathrm{M})$ for the insertion of thermometers to measure the temperature. The heater $(\mathrm{H})$ is started by sending steam through 


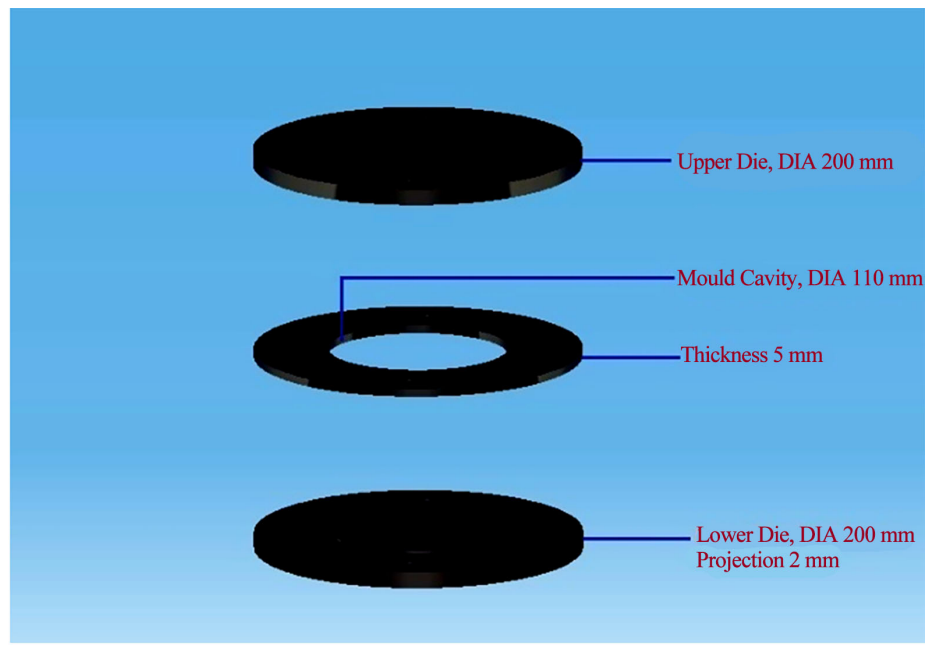

Figure 1. Mould to cast specimens for Lee's Apparatus.

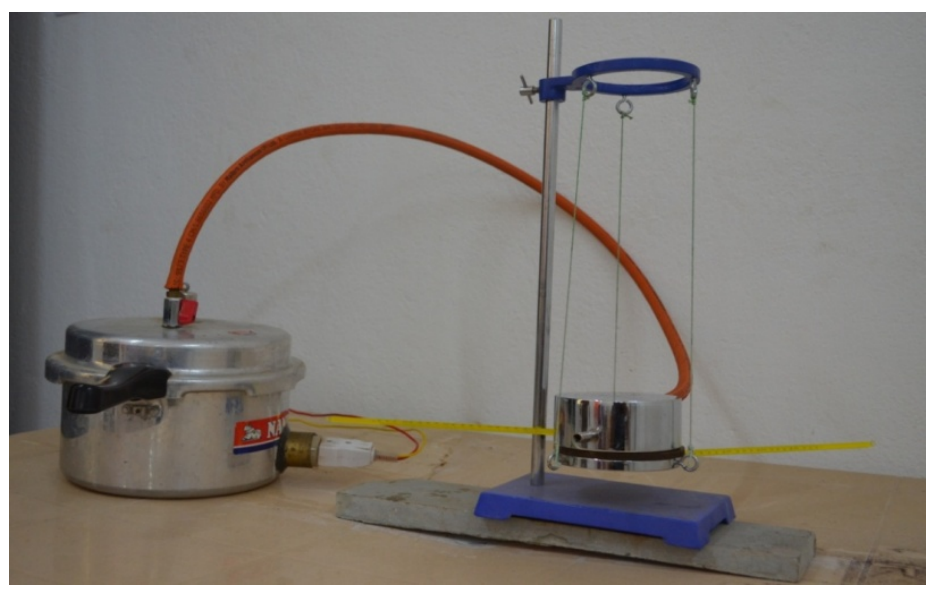

Figure 2. Experimental set up of Lee’s disc Apparatus.

the heating chamber. The temperatures $T_{1}$ and $T_{2}$ are recorded at a regular interval of 5 minutes till they reached the steady state. Then, the supply of steam is cut off and upper nickel disc (N) and specimen or sample disc (S) are removed. Steam is again passed in so that the brass disc is heated to a temperature $10^{\circ} \mathrm{C}$ above the steady state temperature $\mathrm{T}_{2}$. After that the heating chamber is removed and allowed the nickel disc $(\mathrm{N})$ to cool. Temperature is noted in every half a minute until the temperature falls about $10^{\circ} \mathrm{C}$ from steady state temperature $\mathrm{T}_{2}$. Graph is drawn with the time of cooling as abscissa and the temperature of brass disc (B) as ordinate. A tangent is drawn at the steady state temperature $\mathrm{T}_{2}$. The slope of this tangent gives the rate of cooling $\partial T / \partial t$ at steady state temperature $\mathrm{T}_{2}$.

\subsection{Thermal Conductivity Measurement}

Thermal conductivity is a material property that describes the rate at which the heat flows within a body for a given temperature change.

The rate of heat conducted through the specimen or sample is 


$$
Q=K A\left(T_{1}-T_{2}\right) / L
$$

where, $L$ is the thickness of the sample, $A$ is the area of cross section of the sample, $K$ is the thermal conductivity, $Q$ is the rate of heat transfer and $\left(T_{1}-T_{2}\right)$ is the temperature difference.

The rate of heat lost by the brass disc (B) to the surrounding under steady state is

$$
Q=m c(\partial T / \partial t)_{T_{2}}
$$

where, $m$ is the mass of brass disc (B), $c$ is the specific heat of the brass disc (B) and $(\partial T / \partial t)$ is it's rate of cooling at $T_{2}$.

Comparing Equations (5) and (6)

$$
K=m c(\partial T / \partial t)_{T_{2}} / A\left(T_{1}-T_{2}\right) / L
$$

$(\partial T / \partial t)_{T_{2}}$ and $\left(T_{1}-T_{2}\right)$ is calculated using Lee's disc apparatus. Giving the input value of mass of brass disc (B), specific heat of the brass disc, thickness of the sample and area of cross section of the of the sample, the thermal conductivity of the sample is calculated.

\subsection{Thermal Conductivity Models}

Many theoretical and empirical models have been proposed to predict the effective thermal conductivity of two phase mixtures. For a two component composite the simplest alternative would be with the materials arranged in either parallel or series with respect to heat flow, which gives the upper and lower bounds of effective thermal conductivity (Equations (1) and (2)).

\subsection{Series Model (Rule of Mixture)}

$$
\frac{1}{K_{c}}=\frac{1-\phi}{K_{m}}+\frac{\phi}{K_{f}}
$$

where $c$ composite, $m$ : matrix, ff filler, $\phi$ : volume fraction.

\subsection{Parallel Model}

$$
K_{c}=(1-\phi) K_{m}+\phi K_{f}
$$

where $K_{c}$ : Thermal conductivity of composite, $K_{m}$ : Thermal conductivity of matrix, $K_{\dot{f}}$ Thermal conductivity of filler and $\phi$ : is the volume fraction of the filler.

In fact, one can use the series model or parallel model alone or both models according to the practical circumstances.

\subsection{Maxwell Model}

Maxwell [2] using potential theory obtained an exact solution for the conductivity of randomly distributed and non-interacting homogeneous sphere in homogeneous medium as indicated in Equation (10). 


$$
K_{c}=K_{m}\left[\frac{K_{f}+2 K_{m}+2 \phi\left(K_{f}-K_{m}\right)}{K_{f}+2 K_{m}-\phi\left(K_{f}-K_{m}\right)}\right]
$$

\section{Numerical Analysis}

Nowadays, Finite Element Method (FEM) is one of the important numerical analysis methods in the design or modeling of a physical phenomenon in various engineering disciplines. Its basis relies on the decomposition of the domain into a finite number of sub-domains (elements) for which the systematic approximate solution is constructed by applying the variational or weighted residual methods. In effect, FEM reduces the problem to that of a finite number of unknowns by dividing the domain into elements and by expressing the unknown field variable in terms of the assumed approximating functions within each element. These functions (also called interpolation functions) are defined in terms of the values of the field variables at specific points, referred to as nodes. Nodes are usually located along the element boundaries and they connect adjacent elements. The ability to discretize the irregular domains with finite elements makes the method a valuable and practical analysis tool for the solution of boundary, initial and eigenvalue problems arising in various engineering disciplines.

The FEM is thus a numerical procedure that can be used to obtain solutions to a large class of engineering problems involving stress analysis, heat transfer, fluid flow etc. ANSYS is general-purpose finite-element modeling package for numerically solving a wide variety of mechanical problems that include static/dynamic, structural analysis (both linear and nonlinear), heat transfer, and fluid problems, as well as acoustic and electromagnetic problems.

\section{Results and Discussions}

\subsection{Experimental Analysis}

Figure 3 shows the experimental thermal conductivity of rice husk filled epoxy composites with varied proportion of rice husk. The figure shows that with increase of rice husk $\%$ in composites, the thermal conductivity of the composites decreases and there by improves its insulation capability. This reduction might have been attributed due to the voids present in the packing of the fibres \& fibre-fibre matrix ratio and also the thermal conductivity of rice husk. The rice husk filled epoxy composites that have low density yielded low value of thermal conductivity. As the density decreased the voids present in between the fibres increased resulting lower thermal conductivity. Hence with addition of $10 \mathrm{Vol} . \%, 20 \mathrm{Vol} . \%, 30 \mathrm{Vol} . \%$, $40 \mathrm{Vol} . \%$ \& $50 \%$ of rice husk, the thermal conductivity of epoxy resin dropped by $8.4 \%, 58 \%, 67.7 \% 77.7 \%$ and $84.5 \%$ for $200 \mu \mathrm{m}$ size (rice husk) respectively. The values of thermal conductivities of composite with two components i.e. epoxy and rice husk are given in $\mathrm{Ta}$ ble 2 . 


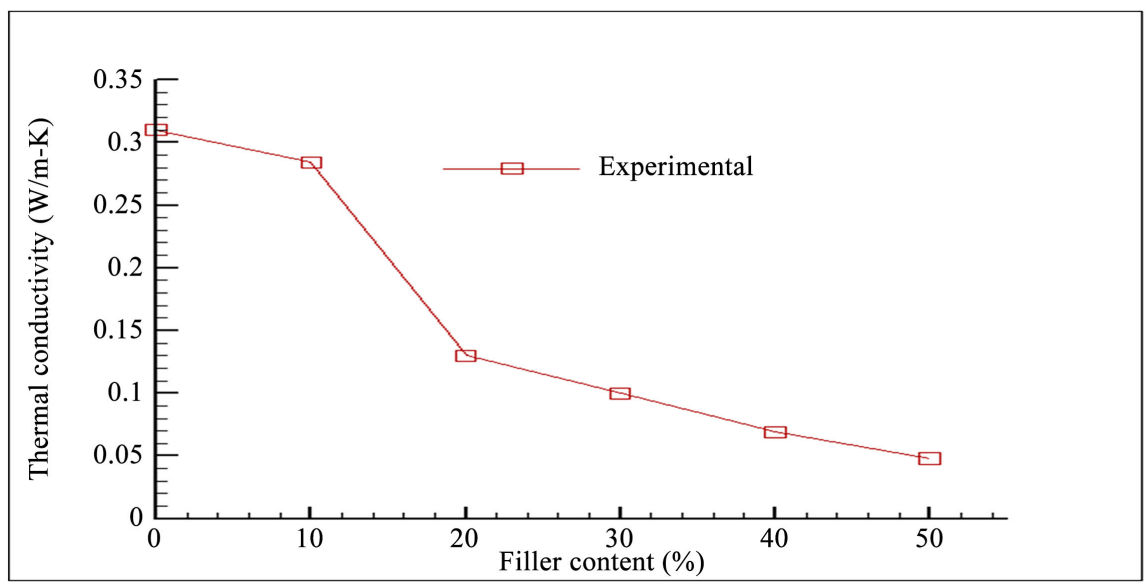

Figure 3. Thermal conductivity of epoxy composites as a function of filler content (Rice husk).

Table 2. Measured thermal conductivity values of composites of varied composition (200 $\mu \mathrm{m}$, Rice husk).

\begin{tabular}{cccc}
\hline Sample & $\begin{array}{c}\text { Particulate } \\
\text { content (Vol.\%) }\end{array}$ & $\begin{array}{c}\text { Experimental value of thermal } \\
\text { conductivity (W/m-K) }\end{array}$ & $\begin{array}{c}\text { \% reduction of thermal } \\
\text { conductivity with respect to } \\
\text { neat epoxy }\end{array}$ \\
\hline 1 & O(neat epoxy) & 0.310 & 0 \\
2 & 10 & 0.284 & 8.4 \\
3 & 20 & 0.130 & 58 \\
4 & 30 & 0.100 & 67.7 \\
5 & 40 & 0.069 & 77.7 \\
6 & 50 & 0.048 & 84.5 \\
\hline
\end{tabular}

In Figure 4, the effective thermal conductivities values obtained from the experimental study for the particulate filled epoxy composites with varied proportions of rice husk are compared with Rule of Mixture thermal conductivity model, Parallel thermal conductivity model and Maxwell thermal conductivity model. It is noticed that the experimental results and all three models are close to each other at low fibre content. It has been found that the thermal conductivity of experimental study and all other three models are decreased with increase of filler contents. On comparison, it has been found that the errors associated with Rule of mixture model, Parallel model and Maxwell correlations with respect to experimental ones lie in the range of $5.4 \%$ to $38 \%, 0.7 \%$ to $260 \%$ and $3.9 \%$ to $250 \%$ respectively. The values of thermal conductivities and percentage of errors associated with each method for individual composite with two components i.e. epoxy and rice husk are given in Table 3 and Table 4 respectively.

\subsection{Numerical Analysis}

In the numerical analysis of the heat conduction problem, the temperatures at the nodes along the surfaces $\mathrm{ABCD}$ is prescribed as T1 (1000C) and the convec- 
tive heat transfer coefficient of ambient is assumed to be $2.5 \mathrm{~W} / \mathrm{m}^{2}-\mathrm{K}$ at ambient temperature of $27^{\circ} \mathrm{C}$. The heat flow direction and the boundary conditions are shown in Figure 5. The other surfaces parallel to the direction of the heat flow are all assumed adiabatic. The temperatures at the nodes in the interior region and on the adiabatic boundaries are unknown. These temperatures are obtained with the help of finite-element program package ANSYS.

Figure 6 compares the results of FEM with those found from experiments. On comparison it is found that the thermal conductivity in both cases is decreased with increase of volume fraction of rice husk in the composites. The thermal conductivities of both the methods are very close to each other. The slight deviations between these two are due to the assumptions taken for the FEM analysis is not real. The shape of rice husk is assumed to be spherical, while in actual practice they are irregular shaped. Although the distribution of rice husk in the matrix body is assumed to be in an arranged manner, it is actually dispersed in the resin almost randomly. The values of thermal conductivities of composite with two components i.e. epoxy and rice husk for numerical analysis are given in Table 5.

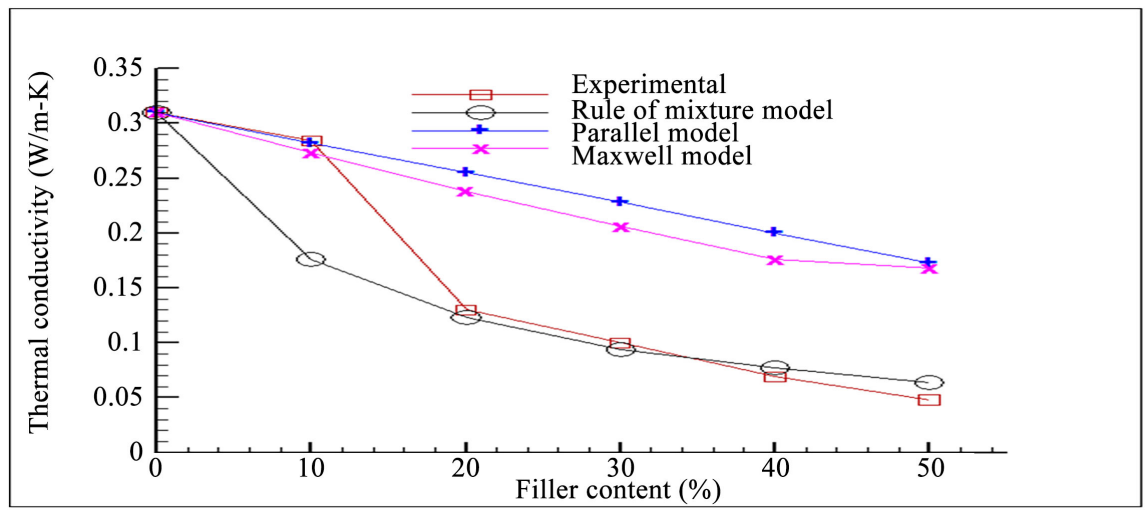

Figure 4. Comparison of thermal conductivity values obtained from different model.

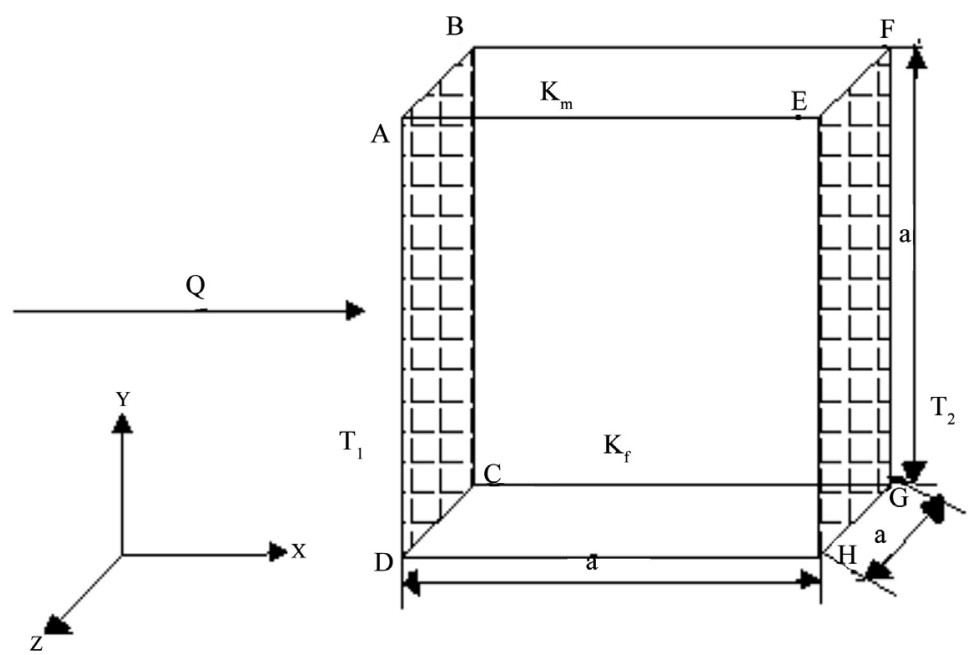

Figure 5. Boundary conditions. 


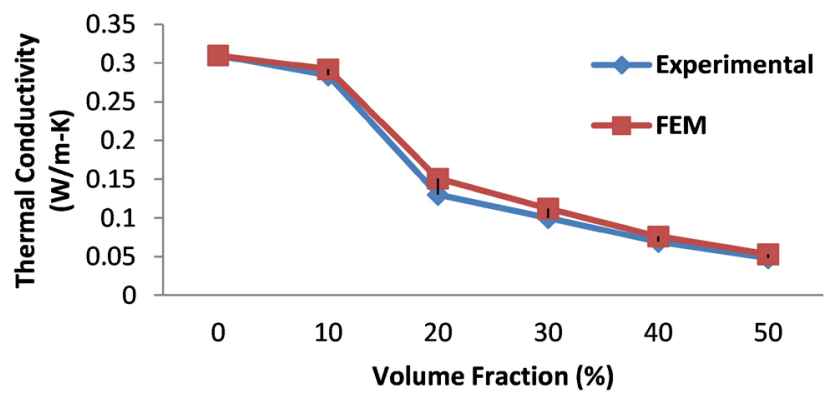

Figure 6. Thermal conductivity of epoxy composites as a function of filler content.

Table 3. Thermal conductivity values of composites obtained from different methods.

\begin{tabular}{cccccc}
\hline Sample & $\begin{array}{c}\text { Filler } \\
\text { Content } \\
(\text { Vol\%) }\end{array}$ & $\begin{array}{c}\text { Rule of } \\
\text { mixture } \\
\text { model }\end{array}$ & $\begin{array}{c}\text { Parallel } \\
\text { model }\end{array}$ & $\begin{array}{c}\text { Maxwell } \\
\text { model }\end{array}$ & Experimental \\
\hline $\mathbf{1}$ & 0 & 0.310 & 0.310 & 0.310 & 0.310 \\
$\mathbf{2}$ & 10 & 0.176 & 0.282 & 0.273 & 0.284 \\
$\mathbf{3}$ & 20 & 0.123 & 0.255 & 0.238 & 0.130 \\
$\mathbf{4}$ & 30 & 0.094 & 0.228 & 0.206 & 0.100 \\
$\mathbf{5}$ & 40 & 0.077 & 0.2 & 0.176 & 0.069 \\
$\mathbf{6}$ & 50 & 0.064 & 0.173 & 0.168 & 0.048 \\
\hline
\end{tabular}

Table 4. Percentage errors with respect to the measured value.

\begin{tabular}{ccccc}
\hline \multirow{2}{*}{ Sample } & $\begin{array}{c}\text { Fibre Content } \\
\text { (Vol\%) }\end{array}$ & \multicolumn{3}{c}{ Percentage errors with respect to Experimental values } \\
\cline { 3 - 5 } & Rule of mixture model & Parallel model & Maxwell model \\
\hline $\mathbf{1}$ & 0 (Epoxy) & 0 & 0 & 0 \\
2 & 10 & 38 & 0.7 & 3.9 \\
$\mathbf{3}$ & 20 & 5.4 & 96.1 & 83 \\
4 & 30 & 6 & 128 & 106 \\
$\mathbf{5}$ & 40 & 11.6 & 190 & 155 \\
$\mathbf{6}$ & 50 & 33.3 & 260 & 250 \\
\hline
\end{tabular}

Table 5. Numerical Thermal conductivity values of composites of varied composition (200 $\mu \mathrm{m}$, Rice husk).

\begin{tabular}{ccc}
\hline Sample & Particulate content (Vol.\%) & $\begin{array}{c}\text { Experimental value of thermal } \\
\text { conductivity (W/m-K) }\end{array}$ \\
\hline $\mathbf{1}$ & 0 (neat epoxy) & 0.310 \\
$\mathbf{2}$ & 10 & 0.292 \\
$\mathbf{3}$ & 20 & 0.151 \\
$\mathbf{4}$ & 30 & 0.112 \\
$\mathbf{5}$ & 40 & 0.076 \\
$\mathbf{6}$ & 50 & 0.048 \\
\hline
\end{tabular}




\section{Conclusion}

An environmental waste like rice husk can be gainfully utilized for preparation of composites using hand-lay-up technique. Incorporation of rice husk results in reduction of thermal conductivity of epoxy resin and thereby improves its thermal insulation capability. It has been found that the thermal conductivity of composites made of rice husk is decreased with increase of filler content. With addition of $10 \%$ of rice husk, the thermal conductivity drops by about $8.4 \%$ and with addition of $50 \%$ of rice husk, the thermal conductivity drops by about $84.5 \%$ in neat epoxy. With light weight and good thermal properties, the rice husk reinforced epoxy composite can be used for preparation of insulation boards, air craft components and furniture etc.

\section{Acknowledgements}

Dr. Ramesh Chandra Mohapatra was born in Orissa, India in 1969. He graduated from Department of Mechanical Engineering of UCE, Burla, now VSSUT, Burla, Orissa, India. He received the degree of M. Tech in Thermal Engineering from Department of Mechanical Engineering of Indian Institute of Technology (IIT), Kharagpur, India in 2011 and $\mathrm{PhD}$ in Mechanical Engineering from Utkal University, Vanivihar, Bhubaneswar, Orissa, India in 2015. He is presently working as Associate Professor \& HOD of Mechanical Engineering Department in Government College of Engineering, Keonjhar, Orissa, India.

\section{References}

[1] Russell, H.W. (1935) Principles of Heat Flow in Porous Insulators. Journal of the American Ceramic Society, 18, 1-5. https://doi.org/10.1111/j.1151-2916.1935.tb19340.x

[2] Maxwell, J.C. (1954) A Treaties on Electricity and Magnetism. 3rd Edition, Dover, New York.

[3] MacLean, J.D. (1941) Thermal Conductivity of Wood. Heating, Piping \& Air Conditioning, 13, 380-391.

[4] Kollmann, F. (1951) Tecnologie des Holzes under Holzwerkstoffe/Franz Kollmann. Springer, Berlin.

[5] Wikes, K.E. (1981) Thermo-Physical Properties Data Base Activities at Owens-Corning Fiberglas. In: Thermal Performance of the Exterior Envelopes of Buildings, ASHRAE SP 28, American Society of Heating, Refrigerating and Air-Conditioning Engineers, Atlanta, 662-677.

[6] TenWolde, A., McNatt, J.D. and Krahn, L. (1988) Thermal Properties of Wood and Wood Panel Products for Use in Buildings. Oak Ridge National Laboratory. http://www.fpl.fs.fed.us/documnts/pdf1988/tenwo88a.pdf

[7] Kamke, F.A. (1989) Effects of Wood-Based Panel Characteristics on Thermal Conductivity. Forest Production Journal, 39, 19-24.

[8] Kumar, R.A., Alok, S., Kumar, S.A. and Kumar, J.D. (2014) A Study on Evaluation of Mechanical and Thermal Properties of Rice Husk Filled Epoxy Composites. 5th International \& 26th All India Manufacturing Technology, Design and Research Conference (AIMTDR 2014), 12-14 December 2014, 828.1-828.5. 
[9] Chandra, M.R., Antaryami, M. and Bhushan, C.B. (2014) Measurement on Thermal Conductivity of Pine Wood Dust Filled Epoxy Composites. American Journal of Mechanical Engineering, 2, 114-119. https://doi.org/10.12691/ajme-2-4-3

[10] Vishnu and Manavendra, G. (2016) Experimental Investigation on Thermal Properties of Fly Ash Reinforced Epoxy Composite. International Journal of Innovative Research in Science, Engineering and Technology, 5, 20723-20729. 